\title{
Genetic Deficiency of Signaling via Interferon Receptors
}

\author{
A review of: Dupuis S, Jouanguy E, Al-Hajjar S et al. 2003 Impaired response to interferon- $\alpha / \beta$ and lethal viral \\ disease in human STAT1 deficiency. Nat Genet 33:388-391
}

$\mathrm{M}$ UTATIONS IN SEVERAL disease genes have been identified in patients with primary immunodeficiency diseases (PIDs) over the past decades (1). The impact of the knowledge gained from studies of new PID entities on our understanding of functions of the immune system including host defense mechanisms to infections, is tremendous. One example is the discovery of mutations that impair functions of receptors (R) or cytokines of the interferon (IFN)- $\gamma /$ interleukin (IL)-12 activation pathway. Deficiencies of IFN$\gamma \mathrm{R} 1$, IFN- $\gamma \mathrm{R} 2$, IL-12Rß1, and IL12 p40 are all predisposing patients to infections by weakly virulent mycobacteria (2). IL-12Rß1 and IL12p40 defects also impair IL23 immunity (2).

Activation of the IFN- $\gamma /$ IL- 12 pathway begins with the production of IL-12 by macrophages responding either to microbial products or to direct infection and subsequent induction, by IL-12, of IFN- $\gamma$ production by NK cells (3). Engagement of the IFN- $\gamma \mathrm{R}$ leads to a complex series of molecular changes at the plasma membrane, in the cytoplasm, and at the nucleus, which results in macrophage activation. Signaling via the IFN- $\gamma \mathrm{R}$ involves components of the Janus kinase (JAK)-signal transducer and activator of transcription (STAT) pathway (4).

Dupuis et al have recently described homozygous mutations with respect to the STAT-1 alleles in two unrelated

Supported by OTKA T 38095.

\section{LÁszLó MARÓdI}

infants suffering, similarly to patients with IFN- $\gamma \mathrm{R}$ or IL-12R deficiency, from mycobacterial infection (5). However, in contrast to patients with receptor deficiencies, these infants had severe viral diseases and they ultimately died of viral infection. One of the patients had recurrent encephalitis caused by herpes simplex virus (HSV)-1. The authors suggest that the striking difference in the clinical phenotype may be due to subtle molecular differences in activation of STAT-1 through IFN $-\alpha / \beta \mathrm{R}$, on one hand, and IFN- $\gamma \mathrm{R}$, on the other.

Binding of both IFN- $\alpha / \beta \mathrm{R}$ and IFN- $\gamma \mathrm{R}$ to their natural ligands activates components of the JAK-STAT signaling pathway leading to the formation of at least two transcription factor complexes (4). STAT-1 is a convergent point for immunologic stimuli in a macrophage proinflammatory response (6). STAT-1 interacts with STAT-2 and p48/IRF9 to form the transcription factor IFN-stimulated gene factor 3 (ISGF3) whereas STAT-1 dimers form $\gamma$-activated factor (GAF) $(4,5)$. ISGF3 plays a central role in IFN- $\alpha / \beta$ R-mediated signaling, whereas GAF is induced mainly by IFN- $\gamma$. Although both transcription factors can be activated by both types of interferon, in this view, STAT-1 activation may lead to the assembly of multiple and varied complexes $(5,6)$.
The etiology of the deadly viral disease was defined in only one of the patients and it is not clear from this study whether homozygous STAT-1 deficiency predisposes patients to severe HSV-1 infections only. Nevertheless, this is the first report in humans to show clearly the protective role of IFN $\alpha / \beta$ in host defense against viral infection.

HSV infection in neonates is a severe disease with high mortality and morbidity in spite of the development of effective anti-viral therapies (7). Herpes simplex encephalitis has to be considered one of the most severe diseases in newborns. We found that neonatal monocytes/macrophages are hyporesponsive to activation by IFN- $\gamma$, which could not be explained by decreased number or ligandbinding capacity of IFN- $\gamma$ receptors (8). However, IFN- $\gamma$-induced STAT-1 phosphorylation was severely deficient in cord mononuclear phagocytes compared to that of adult cells (9). These findings and the observation presented in the paper by Dubuis et al raises the interesting possibility that the unusual severity of HSV-1 infection in newborns may also be related, at least in part, to deficient JAK-STAT-mediated signaling. Development of approaches and techniques capable of detecting more precisely these complicated molecular interactions and dynamics is a challenge of future research. 
1. Valiaho J, Pusa M, Ylinen T, Vihinen M 2002 IDR: the Immunodeficiency Resource. Nucleic Acids Res 30:232-234

2. Fieschi C, Casanova JL 2003 The role of interleukin-12 in human infectious diseases: only a faint signature. Eur J Immunol 33:1461-1464

3. Casanova JL, Abel L 2002 Genetic dissection of immunity to mycobacteria: the human model. Annu Rev Immunol 20:581-620

4. O'Shea JJ 1977 Jaks, STATs, cytokine signal transduction, and immunoregulation. Immunity 7:1-11

5. Dupuis S, Jouanguy E, Al-Hajjar S, Fieschi C, AlMohsen IZ, Al-Jumaah S, Yang K, Chapgier A, Eidenschenk C, Eid P, Al Ghonaium A, Tufenkeji H, Frayha H, Al-Gazlan S, Al-Rayes H, Schreiber RD, Gresser I, Casanova JL 2003 Impaired response to interferon- $\alpha / \beta$ and lethal viral disease in human STAT1 deficiency. Nat Genet 33:388-391
6. Stark GR, Kerr IM, Williams BR, Silverman RH, Schreiber RD 1998 How cells respond to interferons. Annu Rev Biochem 67:227-264

7. Kimberlin DW, Lin CY, Jacobs RF, Powell DA, Frenkel LM, Gruber WC, Rathore M, Bradley JS, Diaz PS, Kumar M, Arvin AM, Gutierrez K, Shelton M, Weiner LB, Sleasman JW, de Sierra TM, Soong SJ, Kiell J, Lakeman FD, Whitley RJ, National Institute of Allergy and Infectious Diseases Collaborative Antiviral Study Group 2001 Natural history of neonatal herpes simplex virus infections in the acyclovir era. Pediatrics 108:223-229

8. Maródi L, Kaposzta R, Campbell DE, Polin RA, Csongor J, Johnston RB Jr 1994 Candidacidal mechanisms in the human neonate. Impaired IFN- $\gamma$ activation in newborn infants. J Immunol 153:56435649

9. Maródi L, Goda K, Palicz A, Szabó G 2001 Cytokine receptor signaling in neonatal macrophages: defective STAT-1 phosphorylation in response to stimulation with IFN-gamma. Clin Exp Immuno $126: 456-460$

Department of Infectology and Pediatric Immunology

Medical and Health Science Center

Email: University of Debrecen

Nagyerdei krt. 98, H-4012

Debrecen, Hungary

Email:Imarodi@jaguar.dote.hu

DOI: 10.1203/01.PDR.0000108692.21824.3E 